\title{
Latent class analysis stratifies mortality risk in patients developing acute kidney injury after high-risk intraabdominal general surgery: a historical cohort study
}

\section{L'analyse de classe latente stratifie le risque de mortalité chez les patients développant une insuffisance rénale aiguë après une chirurgie générale intra-abdominale à risque élevé : une étude de cohorte historique}

\author{
Minjae Kim, MD, MS (1) - Melanie M. Wall, PhD • Ravi P. Kiran, MD • Guohua Li, MD, DrPH
}

Received: 8 May 2018/Revised: 11 July 2018/Accepted: 11 July 2018/Published online: 12 September 2018

(C) Canadian Anesthesiologists' Society 2018

\begin{abstract}
Purpose Risk stratification for postoperative acute kidney injury (AKI) evaluates a patient's risk for developing this complication using preoperative characteristics. Nevertheless, it is unclear if these characteristics are also associated with mortality in patients who actually develop this complication, so we aimed to determine these associations.

Methods The 2011-15 American College of Surgeons National Surgical Quality Improvement Program was used to obtain a historical, observational cohort of high-risk intraabdominal general surgery patients with AKI, which was
\end{abstract}

Electronic supplementary material The online version of this article (https://doi.org/10.1007/s12630-018-1221-0) contains supplementary material, which is available to authorized users.

Presented at the American Society of Anesthesiologists' Annual Meeting, October 22, 2017, Boston, MA.

M. Kim, MD, MS $(\bowtie) \cdot$ G. Li, MD, DrPH

Department of Anesthesiology, Columbia University Medical Center, 622 West 168th Street, PH 5, Suite 505C, New York, NY 10032, USA

e-mail:mk2767@cumc.columbia.edu

M. Kim, MD, MS · G. Li, MD, DrPH

Department of Epidemiology, Mailman School of Public Health, Columbia University, New York, NY, USA

M. M. Wall, PhD

Department of Biostatistics, Mailman School of Public Health, Columbia University, New York, NY, USA

R. P. Kiran, MD

Division of Colorectal Surgery, Department of Surgery,

Columbia University Medical Center, New York, NY, USA defined as an increase in serum creatinine $>177 \mu \mathrm{mol} \cdot \mathrm{L}^{-1}$ (2 $\mathrm{mg} \cdot \mathrm{dL}^{-1}$ ) above the preoperative value and/or the need for dialysis. Latent class analysis, a model-based clustering technique, classified patients based on preoperative comorbidities and risk factors. The associations between the latent classes and the time course of AKI development and mortality after AKI were assessed with the Kruskall-Wallis test and Cox models.

Results A seven-class model was fit on 3,939 observations (derivation cohort). Two patterns for the time course of AKI diagnosis emerged: an "early" group (median [interquartile range] day of diagnosis 3 [1-10]) and a "late" group (day 9 [3-16]). Three patterns of survival after AKI diagnosis were identified (groups A-C). Compared with the group with the lowest mortality risk (group A), the hazard ratios (95\% confidence intervals) for 30-day mortality were 1.79 [1.55 to 2.08] for group $B$ and 3.55 [3.06 to 4.13] for group $C$. These differences in relative hazard were similar after adjusting for the postoperative day of AKI diagnosis and surgical procedure category.

Conclusions Among patients with AKI after high-risk general surgery, the preoperative comorbid state is associated with the time course of and survival after AKI. This knowledge can stratify mortality risk in patients who develop postoperative AKI.

\section{Résumé}

Objectif La stratification du risque d'insuffisance rénale aiguë (IRA) postopératoire évalue le risque de survenue de cette complication en fonction des caractéristiques 
préopératoires des patients. Néanmoins, on ignore si ces caractéristiques sont également associées à la mortalité chez les patients développant cette complication. Nous avons cherché à préciser ces associations.

Méthodes Le programme national d'amélioration de la qualité de la chirurgie 2011-15 de l'American College of Surgeons (ACS NSQIP) a été utilisé pour obtenir une cohorte observationnelle historique de patients de chirurgie générale intra-abdominale à risque élevé de IRA qui était défini par une augmentation de la créatinine sérique $>177 \mu \mathrm{mol} \cdot \mathrm{L}^{-1}\left(2 \mathrm{mg} \cdot d \mathrm{~L}^{-1}\right)$ au-dessus de sa valeur préopératoire et/ou le besoin de dialyse. Une analyse de classe latente (une technique de regroupements basée sur un modèle) a classé les patients en fonction des comorbidités préopératoires et des facteurs de risque. Les associations entre les classes latentes et l'évolution de l'IRA et la mortalité après IRA ont été évaluées au moyen du test de Kruskall-Wallis et des modèles de Cox.

Résultats Un modèle à sept classes a été adapté à partir de 3939 observations (cohorte de dérivation). Concernant le diagnostic des IRA, deux regroupements ont vu le jour : un groupe "précoce " (établissement du diagnostic [plage interquartile] à 3 [1 à 10] jours) et un groupe " tardif » (9 [3 à 16] jours). Trois types de survie après le diagnostic de IRA (groupes A à C) ont été identifiés. Comparativement au groupe ayant le risque de mortalité le plus faible (Groupe A), les rapports de risques (intervalles de confiance à 95\%) pour la mortalité à 30 jours étaient de 1,79 [1,55 à 2,08] pour le Groupe B et de 3,55 [3,06 à 4,13] pour le Groupe $C$. Ces différences de risque relatif sont restées comparables après l'ajustement pour le jour postopératoire du diagnostic de IRA et la catégorie d'intervention chirurgicale.

Conclusions Parmi les patients présentant des IRA après une chirurgie générale à haut risque, l'état morbide préopératoire a été associé à l'évolution des IRA et à la survie chez les patients qui développent une IRA. Ces informations peuvent permettre de stratifier le risque de mortalité chez les patients développant une IRA postopératoire.

Postoperative acute kidney injury (AKI) affects up to 39\% of patients having a major surgical procedure and is associated with higher mortality, hospital length of stay, and hospital costs. ${ }^{1}$ Furthermore, the effects of AKI on mortality and costs persist beyond the initial hospitalization. $^{2,3}$ In major abdominal surgical procedures, AKI is associated with a 3.5-fold increase in 30-day mortality risk, even after adjusting for other comorbidities and risk factors. ${ }^{4}$ While the harm from postoperative AKI is well-known, it is often not clearly recognized in the clinical setting. ${ }^{5}$

Studies have characterized different aspects of postoperative AKI, including the identification of risk factors, 6,7 understanding variation among different types of general surgery procedures, ${ }^{4}$ and assessing the interaction of AKI with other postoperative complications to increase mortality risk. ${ }^{8}$ Nevertheless, it is not clear if the comorbidities and risk factors that contribute to increased AKI risk also contribute to increased mortality risk. In addition, there is a lack of understanding of the factors associated with mortality among patients that develop this devastating complication. Patients with AKI are a heterogeneous group with differing clinical courses and mortality risks. Understanding these differences will help to improve care by directing resources to those that would receive the greatest benefit.

We hypothesized that patients who develop AKI after undergoing high-risk intraabdominal general surgery procedures could be classified based on their preoperative comorbidities and risk factors, and that these classifications would be associated with the clinical course of postoperative AKI, including subsequent mortality. Using data from the American College of Surgeons National Surgical Quality Improvement Program (ACS-NSQIP), latent class analysis (LCA), ${ }^{9}$ a model-based clustering technique, was used to classify patients with AKI based on their preoperative comorbidities and risk factors. We have previously applied LCA to model a patient's comorbid state as a latent variable and found that the latent classes were significantly associated with postoperative mortality ${ }^{10}$ and complications. ${ }^{11}$ This analysis may help clinicians to better understand the relationships between a patient's baseline comorbidities and the risk of mortality among patients with AKI and may lead to strategies to improve their clinical outcomes.

\section{Methods}

This study was determined to be "Not Human Subjects Research Under 45 CFR 46" by the Columbia University Medical Center Institutional Review Board and did not require further review. This is a historical, observational cohort study of high-risk intraabdominal general surgery inpatients who developed AKI within 30 days of surgery identified using data from the 2011-2015 ACS-NSQIP participant use files. The ACS-NSQIP ${ }^{\mathrm{A}}$ is a validated, prospectively collected national dataset aimed at improving surgical quality and outcomes. ${ }^{12}$ Detailed definitions of

\footnotetext{
A The American College of Surgeons National Surgical Quality Improvement Program and the hospitals participating in the ACSNSQIP are the source of the data used herein; they have not verified and are not responsible for the statistical validity of the data analysis or the conclusions derived by the authors.
} 
individual variables collected by the dataset are available. ${ }^{\mathrm{B}}$ This article adheres to the STROBE guidelines for observational studies. ${ }^{\mathrm{C}}$

\section{Patient selection}

We identified a cohort of patients undergoing high-risk intraabdominal general surgery procedures who did not have preoperative acute renal failure or were receiving dialysis (Supplemental Fig. 1, available as Electronic Supplementary Material [ ESM]). There were 3,274,413 records in the 2011-2015 ACS-NSQIP participant use files. Outpatient procedures were excluded as they had a low risk for AKI. Procedures were classified using the Clinical Classifications Software for Services and Procedures (CCS-SP; Agency for Healthcare Research and Quality, Rockville, MD, USA), ${ }^{\mathrm{D}}$ which is based on the primary Current Procedural Terminology (CPT; American Medical Association, Chicago, IL, USA) code. High-risk CCS-SP categories (Supplemental Table 1, available as ESM) were identified from prior studies. ${ }^{4}$ Of note, "other operating room gastrointestinal therapeutic procedures" contains major hepatobiliary and pancreatic procedures. Preoperative acute renal failure was defined by the dataset as: “... rapid, steadily increasing azotemia (increase in blood urea nitrogen) and a rising creatinine of above $3 \mathrm{mg} \cdot \mathrm{dl}^{-1}\left(265 \mu \mathrm{mol} \cdot \mathrm{L}^{-1}\right)$. Acute renal failure should be noted within $24 \mathrm{hr}$ prior to surgery." Patients with preoperative acute renal failure, as defined by the dataset, or receiving dialysis were excluded.

We initially identified 330,365 patients undergoing high-risk procedures without preoperative acute renal failure or not receiving dialysis. Postoperative AKI was defined by the dataset as “... a rise in creatinine of $>2 \mathrm{mg} \cdot \mathrm{dl}^{-1}\left(177 \mu \mathrm{mol} \cdot \mathrm{L}^{-1}\right)$ from preoperative value ..." and/or the requirement for postoperative dialysis. A random number generator assigned each observation to the derivation or validation cohorts with probabilities of $70 \%$ and $30 \%$, respectively. Of the 5,576 patients with postoperative AKI, 3,939 were assigned to the derivation cohort $(70.6 \%)$ and 1,639 were assigned to the validation (29.4\%) cohort.

\footnotetext{
B Available from URL: https://www.facs.org/ /media/files/quality\% 20programs/nsqip/nsqip_puf_user_guide_2015.ashx (accessed July 2018).

C Available from URL: http://www.strobe-statement.org/index. php?id=available-checklists (accessed July 2018).

D Available from URL: http://www.hcup-us.ahrq.gov/toolssoftware/ ccs_svcsproc/ccssveproc.jsp (accessed July 2018).
}

Baseline demographic and operative variables

In 2011, the ACS-NSQIP introduced an "Essentials" module where centres could report fewer preoperative variables compared with the "Classic" module. Preoperative variables that are only available in the Classic module were excluded as their inclusion would create a substantial number of records with missing data.

Age (in yr) was categorized as: $\leq 40,>40$ to $\leq 50,>50$ to $\leq 60,>60$ to $\leq 70,>70$ to $\leq 80$, and $>80$. Body mass index (BMI) was calculated from height and weight data and categorized into the groups based on World Health Organization guidelines ${ }^{13}: \leq 18.5,>18.5$ to $\leq 25,>25$ to $\leq 30,>30$ to $\leq 35$, and $>35 \mathrm{~kg} \cdot \mathrm{m}^{-2}$. The estimated glomerular filtration rate (eGFR) was calculated using the Chronic Kidney Disease Epidemiology Collaboration formula incorporating creatinine, sex, age, and race ${ }^{14}$ and categorized into groups corresponding to the stages of chronic kidney disease $(\mathrm{CKD})^{15}: \leq 15,>15 \quad$ to $\leq 30,>30$ to $\leq 60,>60$ to $\leq 90,>90 \mathrm{~mL} \cdot \mathrm{min}^{-1} \cdot 1.73 \mathrm{~m}^{-2}$, or missing. Hematocrit (vol\%) was categorized as $\leq 34,>34$ to $\leq$ $38,>38$, or missing based on prior analysis. ${ }^{10}$ Prior history of cancer was determined as described previously. ${ }^{4}$ Other variables were collected directly from the dataset.

\section{Latent class analysis model}

A latent variable is one that cannot be directly observed but is instead inferred from other directly measurable variables. ${ }^{16}$ We have previously applied LCA methodology to model a patient's comorbid state based on their preoperative characteristics. ${ }^{10,11}$ There is no single test or variable to indicate a patient's overall comorbid state, but it can be modelled through known characteristics. An advantage of LCA is that it provides dimensionality reduction, ${ }^{17}$ in this case reducing many comorbidities and risk factors into a smaller number of distinct comorbid states.

Our goal was to model the patient's comorbid state based on their preoperative characteristics and comorbidities, so only patient characteristics were entered into the LCA model. Variables for inclusion in the LCA model were based on prior work ${ }^{10,11}$ and the 21 variables available in the Essentials module (Fig. 1) were entered into LCA models ranging from two classes to nine classes. For each class size, the model attempts to group patients into the specified number of categories so that each group is similar with respect to the variables entered into the model. Models with different numbers of classes were compared based on comparison of the Akaike Information Criterion (AIC), Bayesian Information Criterion (BIC), ${ }^{18}$ sample-size adjusted BIC, and clinical interpretation. ${ }^{19}$ Each patient was assigned to a latent class based on the 


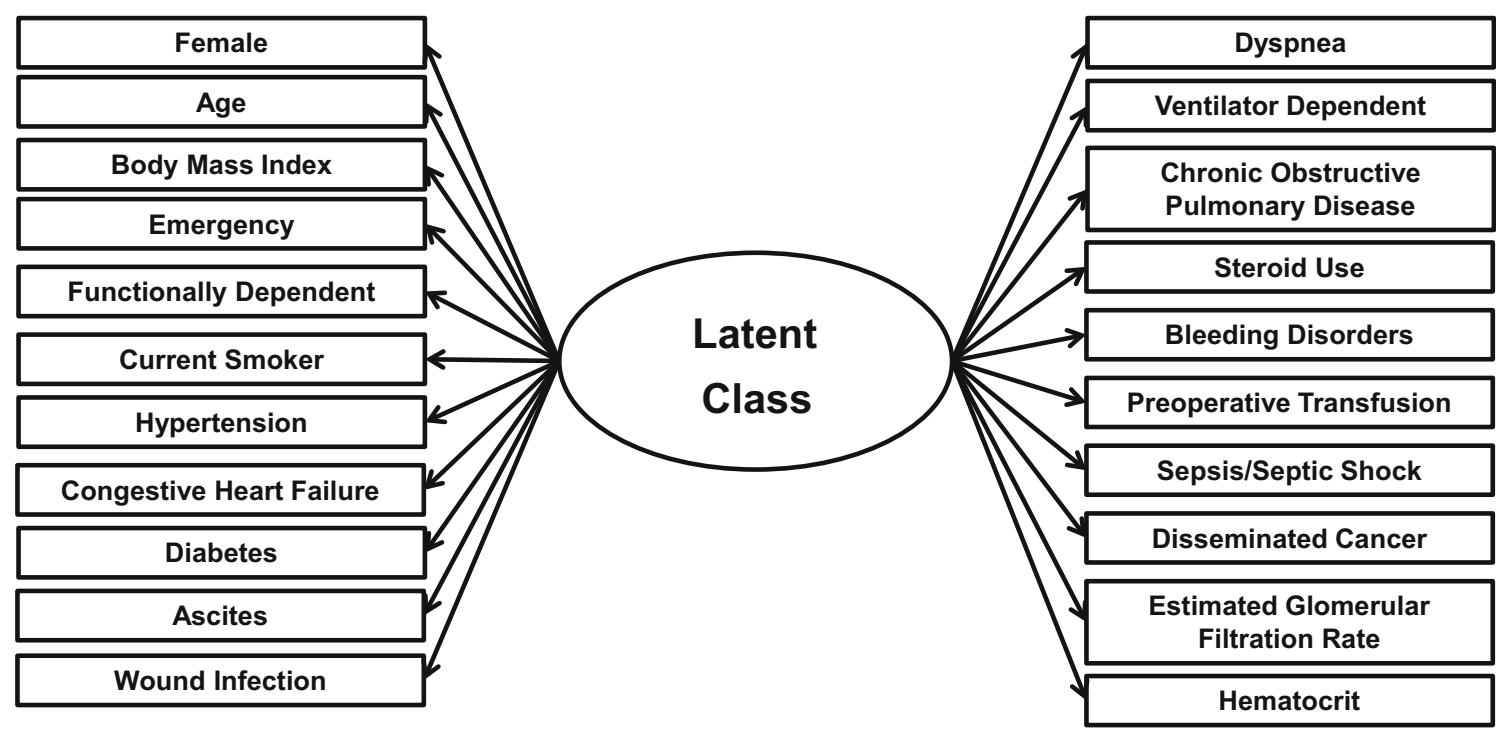

Fig. 1 Variables from the American College of Surgeons National Surgical Quality Improvement Program (2011-2015) dataset used to develop the latent classes for patients who developed acute kidney injury after undergoing high-risk intraabdominal general surgery procedures

highest posterior probability. Full information maximum likelihood was used to account for missing data in the LCA model. ${ }^{20}$ The estimated parameters from the initial LCA model on the derivation cohort were used to estimate the probabilities of class membership in the validation cohort. LCA was performed using Mplus software version 7 (Muthén and Muthén, Los Angeles, CA, USA).

\section{Clinical endpoints}

Patients participating in the ACS-NSQIP are followed for 30 days after their procedure. The dataset identifies the postoperative day (POD) on which AKI was diagnosed and if the patient died within 30 days of the initial procedure.

\section{Statistical analysis}

Differences in the POD of AKI diagnosis among the classes were analyzed using the Kruskal-Wallis test with Dunn's multiple comparisons test. Differences in survival patterns among the latent classes were analyzed using the Kaplan-Meier estimator ${ }^{21}$ and the log-rank test. $^{22}$ Bonferroni correction was applied to account for multiple comparisons when comparing individual latent classes with each other. ${ }^{23}$ Latent classes with similar survival patterns were combined into risk groups. Cox proportional hazard modelling was used to estimate the relative hazard for mortality after the POD of AKI diagnosis, comparing the combined risk groups. Comorbidity and risk factor variables were not entered into Cox models as they were used to determine the latent classes. Additional variables included in the Cox models were the POD of AKI diagnosis and category of procedure (CCS-SP). The POD of AKI diagnosis was linear with respect to the log-hazard for mortality and entered into the models as a continuous variable. Confidence intervals (CIs) for the Cox models were determined using 1,000 bootstrapped samples where the assigned latent risk class for a given patient was allowed to vary based on the posterior probabilities. Interactions between variables in the Cox model were tested by including a cross-product term. Statistical analyses were performed using GraphPad Prism 6.07 (GraphPad Software, Inc, La Jolla, CA, USA) and SAS Software version 9.4 (SAS Institute, Cary, NC, USA). The baseline $\alpha$ for statistical significance was set to 0.05 and adjusted as necessary to account for multiple comparisons using Bonferroni correction.

\section{Sensitivity analyses}

A sensitivity analysis was performed to compare a mortality risk prediction model using the latent classes with a model using individual variables. Cox models were fit for mortality after AKI diagnosis with individual preoperative comorbidities and risk factors used in the latent class models, the surgical procedure category, and the POD of AKI diagnosis. All variables were included in the models and variable selection methods were not utilized.

In addition, a sensitivity analysis was performed to compare risk classes from preoperative risk stratification with risk classes from stratification after the development of AKI. For preoperative risk stratification, we used data 
from a prior analysis of intraabdominal general surgery procedures using a nine-class LCA model. ${ }^{10}$ Data for both models were available for 347 patients in the 2011 ACSNSQIP dataset.

\section{Results}

Determining the latent class model

Latent class models were fit based on 21 preoperative comorbidities and risk factors (Fig. 1) using the 3,939 observations in the derivation cohort, ranging from two classes to nine classes (Supplemental Table 2, available as ESM). The lowest BIC value occurred in the seven-class model, while the AIC and sample-sized adjusted BIC continued to decline up to nine classes. Based on these statistics and accounting for clinical interpretability, we chose to use the seven-class model as having the best fit for further analysis. Missing data were present for female $(n=1 ; 0.0 \%)$, BMI $(n=120 ; 3.0 \%)$, and functionally dependent $(n=1.0 \%)$. Records with missing data for hematocrit $(n=42 ; 1.1 \%)$ and eGFR $(n=57 ; 1.4 \%)$ were coded as a distinct category. With seven latent classes, there are 21 distinct combinations of two classes; the Bonferroni threshold was $0.05 / 21=0.002$ when comparing latent classes with each other.

Baseline characteristics and description of the latent classes

The baseline characteristics of each latent class and general descriptions of each latent class are presented in Table 1 and Supplemental Table, respectively 3 (available as ESM). (Note: Supplemental Table 3 describes the prevailing characteristics of each latent class but are not the specific criteria used to classify patients.) The classes were numbered by increasing 30-day mortality risk (i.e., class 1 has lowest 30-day mortality risk).

Class $1(n=965 ; 24.5 \%)$ patients were middle aged (age 50-80 yr) with hypertension and mild CKD but lower rates of other comorbidities. Class $2(n=655 ; 16.6 \%)$ patients were young (age $<60 \mathrm{yr}$ ) with few comorbidities and normal eGFR but high rates of cancer. Class $3(n=431 ; 10.9 \%)$ patients were generally older (age $>50 \mathrm{yr}$ ) with high rates of hypertension, diabetes, dyspnea, chronic obstructive pulmonary disease (COPD), mild to moderate CKD, and low hematocrit values. Class $4(n=736 ; 18.7 \%)$ patients were older (age $>70 \mathrm{yr}$ ) with hypertension and mild to moderate CKD but low rates of other comorbidities.

Class $5 \quad(n=369 ; 9.4 \%)$ patients were younger (age $<70 \mathrm{yr}$ ) with mild to moderate CKD but had high rates of sepsis/septic shock, mechanical ventilation, and emergent procedures. Class $6(n=493 ; 12.5 \%)$ patients were older (age $>60 \mathrm{yr}$ ), had high rates of comorbidities such as hypertension, congestive heart failure, COPD, mechanical ventilation, moderate to severe CKD, and sepsis/septic shock, and received emergent procedures. Class $7 \quad(n=290 ; 7.4 \%)$ patients received emergent procedures and had high rates of comorbidities, mechanical ventilation, sepsis/septic shock, bleeding disorders, preoperative transfusions, and moderate to severe CKD.

The most common procedure category in the overall cohort was "colorectal resection" (59.6\%), followed by "other operating room gastrointestinal therapeutic procedures" (12.4\%; major hepatobiliary and pancreatic procedures), "small bowel resection" (10.3\%), "ileostomy and other enterostomy" (9.0\%), and "exploratory laparotomy" $(5.2 \%)$. The remaining three categories were each less than $5 \%$ of the sample.

Timing of AKI and survival after AKI by latent class

The median (interquartile range [IQR]) POD of AKI diagnosis was POD \#7 [2-14] (Fig. 2A). Among the individual latent classes, there were two distinct patterns with respect to the distribution of the POD of AKI diagnosis as classes 1-4 were not statistically different from each other and classes 5-7 were not statistically different from each other (Fig. 2B; Supplemental Figs 2A-G, available as ESM). The median POD of AKI diagnosis for patients in classes 1-4 were POD 9 [3-16], POD 8 [316], POD 8 [3-15], and POD 8 [3-15] for classes 1, 2, 3, and 4, respectively. The medians for patients in classes 5-7 were POD 3 [1-10], POD 3 [1-10], and POD 3 [1-9], for classes 5, 6, and 7, respectively $(P<0.0001$ when comparing classes 1-4 vs classes 5-7; Bonferroni threshold is 0.002).

Among patients who developed AKI, 30.0\% died within 30 days of their procedure. Thirty-day mortality ranged from $17.6 \%$ in class 1 patients to $54.1 \%$ in class 7 patients (Table 1). Kaplan-Meier curves of survival after AKI diagnosis showed three distinct patterns (Fig. 3A). Survival among patients in classes 1 and 2 were not statistically different, as was survival among patients in classes 3-5, and among patients in classes 6 and 7. Patients in classes 1 and 2 had the best survival $(P<0.001$ compared with classes 3-7; Bonferroni threshold 0.002), followed by patients in classes 3-5 $(P<0.001$ compared with classes 1 2 and 6-7; Bonferroni threshold 0.002), while patients in classes 6-7 had the poorest survival. Classes with similar survival curves were combined into a single group for further analysis (classes 1 and $2 \rightarrow$ group A; classes 3, 4, and $5 \rightarrow$ group B; and classes 6 and $7 \rightarrow$ group C); these groups retained the distinct survival patterns (Fig. 3B). 
Table 1 Baseline characteristics of the total sample and each latent class in a seven-class latent class analysis model in patients with acute kidney injury after highrisk intraabdominal general surgery procedures, American College of Surgeons National Surgical Quality Improvement Program, 2011-2015

\begin{tabular}{|c|c|c|c|c|c|c|c|c|}
\hline & \multirow[t]{2}{*}{ All } & \multicolumn{7}{|c|}{ Latent class } \\
\hline & & 1 & 2 & 3 & 4 & 5 & 6 & 7 \\
\hline Sample size $(n)$ & 3939 & 965 & 655 & 431 & 736 & 369 & 493 & 290 \\
\hline Percent & & 24.5 & 16.6 & 10.9 & 18.7 & 9.4 & 12.5 & 7.4 \\
\hline Female & 40.6 & 26.4 & 39.9 & 48.3 & 44.7 & 37.4 & 54.6 & 42.6 \\
\hline \multicolumn{9}{|l|}{ Age (yr) } \\
\hline$\leq 40$ & 4.5 & 0.0 & 16.7 & 0.6 & 0.0 & 12.4 & 0.0 & 6.6 \\
\hline$>40$ to $\leq 50$ & 8.0 & 4.2 & 21.4 & 2.4 & 0.0 & 20.3 & 3.2 & 11.1 \\
\hline$>50$ to $\leq 60$ & 19.0 & 25.2 & 32.5 & 18.1 & 0.0 & 30.2 & 7.3 & 23.4 \\
\hline$>60$ to $\leq 70$ & 28.9 & 46.1 & 24.7 & 39.3 & 9.8 & 25.7 & 24.7 & 28.1 \\
\hline$>70$ to $\leq 80$ & 25.4 & 23.7 & 4.7 & 28.2 & 47.7 & 10.3 & 36.1 & 18.1 \\
\hline$>80$ & 14.2 & 0.8 & 0.0 & 11.6 & 42.5 & 1.3 & 28.7 & 12.8 \\
\hline \multicolumn{9}{|l|}{ Body mass index $\left(\mathrm{kg} \cdot \mathrm{m}^{-2}\right)$} \\
\hline$\leq 18.5$ & 2.9 & 0.0 & 4.2 & 2.0 & 3.6 & 3.1 & 5.0 & 5.1 \\
\hline$>18.5$ to $\leq 25$ & 23.7 & 11.3 & 31.8 & 14.0 & 36.7 & 21.8 & 22.2 & 31.2 \\
\hline$>25$ to $\leq 30$ & 29.6 & 31.4 & 28.4 & 24.4 & 37.1 & 26.6 & 27.9 & 24.1 \\
\hline$>30$ to $\leq 35$ & 20.7 & 29.0 & 15.7 & 22.4 & 16.6 & 16.9 & 19.5 & 20.3 \\
\hline$>35$ & 23.1 & 28.3 & 19.9 & 37.3 & 6.0 & 31.6 & 25.4 & 19.2 \\
\hline Emergency & 33.9 & 2.2 & 6.8 & 12.0 & 20.7 & 100.0 & 94.4 & 77.4 \\
\hline Functionally dependent & 9.9 & 0.1 & 1.8 & 20.5 & 10.6 & 5.2 & 22.4 & 23.8 \\
\hline Current smoker & 22.3 & 20.1 & 32.5 & 20.9 & 8.2 & 38.5 & 21.7 & 24.4 \\
\hline Hypertension & 70.6 & 86.3 & 34.2 & 94.7 & 79.4 & 39.5 & 87.2 & 55.4 \\
\hline Congestive heart failure & 4.8 & 0.0 & 0.0 & 14.1 & 3.4 & 2.0 & 14.5 & 6.0 \\
\hline Diabetes & 28.2 & 36.0 & 7.7 & 63.4 & 23.8 & 7.0 & 30.8 & 24.4 \\
\hline Dyspnea & 15.9 & 11.0 & 5.3 & 39.6 & 9.2 & 7.4 & 31.0 & 16.5 \\
\hline Ventilator dependent & 9.3 & 0.0 & 0.0 & 1.9 & 0.0 & 20.0 & 25.4 & 51.8 \\
\hline Chronic obstructive pulmonary disease & 12.6 & 9.1 & 2.2 & 27.9 & 7.9 & 8.5 & 30.8 & 8.2 \\
\hline Ascites & 5.3 & 0.3 & 4.4 & 6.5 & 2.2 & 9.1 & 4.8 & 22.9 \\
\hline Wound infection & 5.9 & 0.1 & 4.1 & 16.0 & 1.9 & 3.8 & 6.2 & 21.8 \\
\hline Steroid use & 10.2 & 4.0 & 10.0 & 14.5 & 6.2 & 10.1 & 18.8 & $\mathbf{1 7 . 0}$ \\
\hline Bleeding disorders & 13.7 & 5.5 & 4.9 & 14.7 & 11.9 & 12.9 & 26.8 & 39.0 \\
\hline Preoperative transfusion & 9.3 & 0.0 & 2.4 & 11.4 & 8.6 & 0.7 & 6.9 & 62.7 \\
\hline Sepsis/septic shock & 32.6 & 1.3 & 9.9 & 22.5 & 11.4 & 88.0 & 91.2 & 81.4 \\
\hline Disseminated cancer & 12.0 & 11.3 & 23.0 & 11.9 & 10.4 & 6.0 & 5.7 & 11.1 \\
\hline \multicolumn{9}{|c|}{ Estimated glomerular filtration Rate $\left(\mathrm{mL} \cdot \mathrm{min}^{-1} \cdot 1.73 \mathrm{~m}^{-2}\right)$} \\
\hline Missing & 1.4 & 3.3 & 2.3 & 0.9 & 0.2 & 0.6 & 0.4 & 0.8 \\
\hline$\leq 15$ & 3.0 & 0.2 & 0.1 & 4.3 & 2.4 & 6.6 & 9.9 & 2.1 \\
\hline$>15$ to $\leq 30$ & 13.6 & 0.6 & 0.1 & 16.0 & 13.8 & 19.0 & 38.6 & 30.2 \\
\hline$>30$ to $\leq 60$ & 27.5 & 18.7 & 7.6 & 35.1 & 40.7 & 27.1 & 37.8 & 36.2 \\
\hline$>60$ to $\leq 90$ & 31.7 & 50.9 & 25.9 & 26.5 & 40.4 & 24.7 & 13.3 & 14.1 \\
\hline$>90$ & 22.7 & 26.4 & 63.9 & 17.1 & 2.6 & 22.0 & 0.0 & 16.5 \\
\hline \multicolumn{9}{|l|}{ Hematocrit (\%) } \\
\hline Missing & 1.1 & 2.8 & 0.6 & 1.7 & 0.0 & 0.9 & 0.2 & 0.0 \\
\hline$\leq 34$ & 40.3 & 12.1 & 35.7 & 68.2 & 47.4 & 25.5 & 35.3 & 94.0 \\
\hline$>34$ to $\leq 38$ & 21.3 & 25.9 & 21.3 & 18.7 & 25.7 & 18.3 & 22.6 & 3.1 \\
\hline$>38$ & 37.4 & 59.2 & 42.4 & 11.4 & 26.9 & 55.3 & 41.8 & 2.9 \\
\hline 30-day mortality & 30.0 & 17.6 & 18.6 & 29.2 & 30.3 & 33.1 & 52.9 & 54.1 \\
\hline
\end{tabular}

Numbers indicate the probability (\%) of a patient within each latent class having the given characteristic based on the model. Percentages in bold indicate that the probability of having the given characteristic in the latent class is significantly different than the probability in the overall sample, using two-sided $t$ test $(\alpha=0.05)$ to test the null hypothesis that the probability within a latent class equals the probability in the entire sample. Thirty-day mortality was not used in the development of the latent class model 

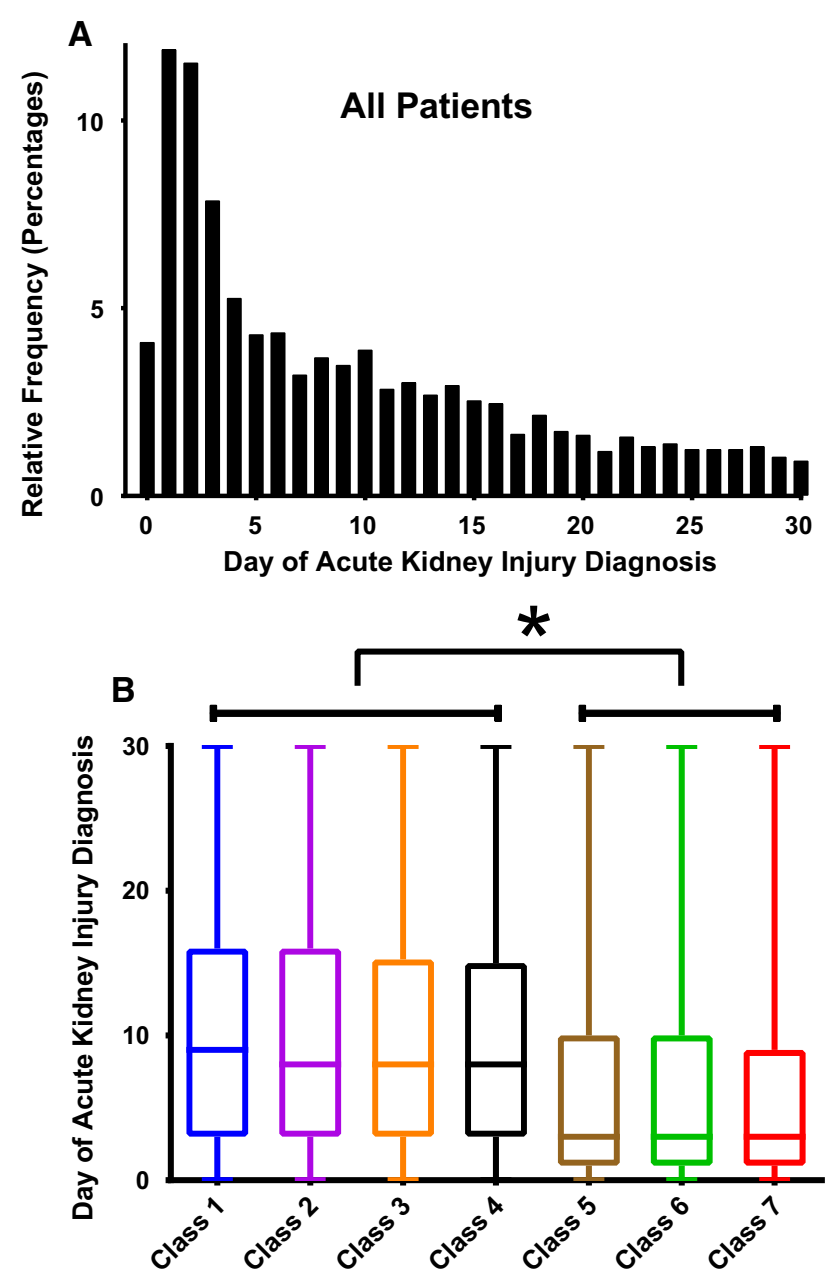

Fig. 2 (A) Histogram of the postoperative day (POD) of acute kidney injury (AKI) diagnosis in all patients undergoing high-risk intraabdominal general surgery developing this complication in the derivation cohort. (B) Box plot of the POD of AKI diagnosis by latent class. $* P<0.0001$ comparing individual classes (classes 1-4 vs classes 5-7) using the Kruskal-Wallis test with multiple comparisons (note: Bonferroni threshold for comparing individual latent classes is 0.002). Data from the American College of Surgeons National Surgical Quality Improvement Program, 2011-2015

Cox models for mortality after postoperative AKI diagnosis

Thirty-day mortality for patients in groups $\mathrm{A}, \mathrm{B}$, and $\mathrm{C}$ were $18 \%, 31 \%$, and $53 \%$, respectively (Table 2). Compared with patients in group A, the group with the lowest mortality risk, the relative hazard for mortality was 1.79 (95\% CI, 1.52 to 2.05) for patients in group B and 3.55 (95\% CI, 2.87 to 3.88) for patients in group C. The relative hazards among the groups did not meaningfully change after adjusting for the POD of AKI diagnosis, or after adjusting for the POD of AKI diagnosis and category of the procedure. The change in the relative hazard for mortality when AKI diagnosis occurred one POD later was 0.97 ( $95 \%$ CI, 0.96 to 0.98 ). We tested whether differences in the hazard for mortality by group were modified by the POD of AKI diagnosis by including an interaction term, but this term was not statistically significant (data not shown). Similar analyses using the seven original classes yielded identical results (data not shown), indicating that grouping patients with similar survival patterns did not affect the interpretation of our results.

\section{Validation of LCA model}

Using the parameters derived from the original seven-class LCA model, we computed the class probabilities for the 1,637 patients in the validation cohort and assigned each to the latent class with the greatest posterior probability. To validate the original model, we compared 30-day mortality (Supplemental Table 4, available as ESM) and KaplanMeier survival after AKI diagnosis in the derivation and validation cohorts for each class (Supplemental Figs. 3AG, available as ESM). For all classes except for class 3, there were no significant differences in 30-day mortality or Kaplan-Meier survival. Nevertheless, for class 3, 30-day mortality in the derivation and validation cohorts were $29.2 \%$ and $40.6 \%$, respectively $(P=0.03)$, and the survival curves were significantly different (log-rank test $P=0.01$ ). Class 3 was combined with classes 4 and 5 to form group $\mathrm{B}$, and there were no significant differences in 30-day mortality $(30.7 \%$ in derivation vs $33.6 \%$ in validation; $P=0.21$ ) or Kaplan-Meier survival (Supplemental Fig. $3 \mathrm{H}$, available as ESM) between the derivation and validation cohorts.

Sensitivity analysis: Cox models for mortality using individual variables

Cox models for mortality after AKI diagnosis using individual preoperative comorbidities and risk factors, the surgical procedure category, and the POD of AKI diagnosis were fit for the entire cohort and separately for each group (A, B, and C) (Table 3).

Sensitivity analysis: comparing preoperative mortality risk with mortality risk after development of AKI

Three hundred and forty-seven patients in the 2011 ACSNSQIP cohort had both preoperative and post-AKI risk stratification data (Supplemental Table 5, available as ESM). The Kendall tau correlation was $-0.339(P<0.001)$.

\section{Discussion}

Preoperative risk stratification is performed on surgical cohorts prior to surgery, ${ }^{10}$ but separate analyses of patients 

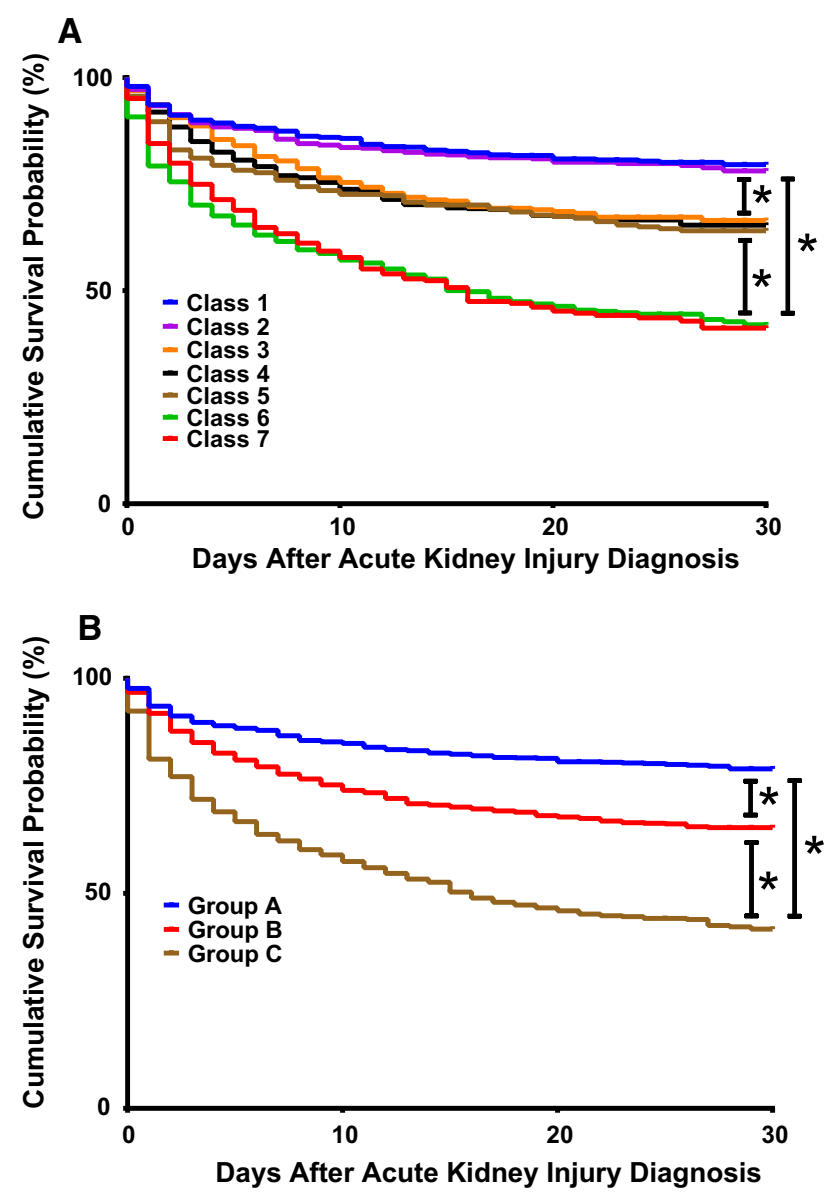

Fig. 3 (A) Kaplan-Meier plots of survival after acute kidney injury diagnosis among patients undergoing high-risk intraabdominal general surgery, derivation cohort, by latent class. $* P<0.0001$ using log-rank test to compare individual classes. (B) Kaplan-Meier plots after classes with similar survival curves were combined into a single group (classes 1 and $2 \rightarrow$ group A; classes 3, 4, and $5 \rightarrow$ group $\mathrm{B}$; and classes 6 and $7 \rightarrow$ group $\mathrm{C}$ ). ${ }^{*} P<0.0001$ using log-rank test to compare groups (note: Bonferroni threshold for comparing individual latent classes is 0.002). Data from the American College of Surgeons National Surgical Quality Improvement Program, 20112015

actually developing a specific complication, such as cardiac arrest, ${ }^{24}$ might yield important prognostic information that preoperative risk stratification alone does not. Here, we focused on patients developing severe AKI after undergoing high-risk intraabdominal general surgery procedures and classified them based on their preoperative comorbidities and risk factors using LCA, ${ }^{10,11}$ a modelbased clustering method designed to identify patients that are similar with respect to the preoperative comorbidities and risk factors entered into the model. ${ }^{9}$ This model classified patients into groups with similar "comorbid states," and it was this comorbid state, and not the individual risk factors, that was used as a predictor for mortality after AKI.
The classes neatly separated patients into groups with three distinct patterns of survival after AKI diagnosis, demonstrating heterogeneity in mortality after AKI that was associated with the preoperative comorbid state. Overall, AKI carried an extremely high mortality, with $30 \%$ of patients dying within 30 days of surgery. The "low" mortality strata (group A) and the "average" mortality strata (group B) each contained approximately $40 \%$ of patients and had mortality of $18 \%$ and $31 \%$, respectively, while the "high" mortality strata (group C) comprised $20 \%$ of the sample and had a mortality of $53 \%$. In addition, the classes were associated with two distinct patterns with regards to the POD in which AKI occurred.

Patients in the highest risk strata (group C) had high rates of emergent procedures, sepsis/septic shock, and mechanical ventilation but there were important distinctions between the two classes comprising this strata. Class 6 patients were defined by a severe comorbidity burden while class 7 patients did not necessarily have the same degree of comorbidities but had severe acute bleeding issues as shown by low hematocrit and preoperative transfusions (Table 1). Another class of patients with high rates of emergent procedures, sepsis/septic shock, and mechanical ventilation (class 5) was nonetheless in the average risk strata (group B). These patients were younger and had lower comorbidity burdens than those in the highest risk strata. Also in the average risk strata was a class of elderly patients (age $>70 \mathrm{yr}$ ) with low BMIs but an average distribution of other comorbidities (class 4) and a class of patients with higher BMIs and high rates of comorbidities such as hypertension, diabetes, and COPD (class 3). Finally, the lowest risk strata (group A) consisted of a class of younger (age $<60 \mathrm{yr}$ ) patients with low rates of comorbidities but high rates of disseminated cancer (class 2 ) as well as a class of patients mainly between the ages of 50 and $80 \mathrm{yr}$ with high rates of hypertension but low rates of other comorbidities (class 1).

An advantage of using latent risk classes was illustrated by examining preoperative renal function, one of the strongest predictors of postoperative AKI. ${ }^{4-6}$ In a traditional regression model, it would not appear as if eGFR had a relationship with mortality, as sensitivity analyses did not show an association between eGFR and the hazard for mortality in the entire cohort as well as within each of the risk groups (Table 3). Nevertheless, careful observation of the distribution of eGFR among the risk classes (Table 1) showed that patients with preoperative renal function in the moderate (eGFR 30-60) to severe (eGFR 15-30) CKD ranges were overrepresented in the high-risk classes (classes 6 and 7) while those in the mild (eGFR 60-90) to normal (eGFR > 90) CKD ranges were overrepresented in the lower risk classes (classes 1 
Table 2 Thirty-day mortality and Cox models for mortality after acute kidney injury diagnosis in high-risk intraabdominal general surgery patients, American College of Surgeons National Surgical Quality Improvement Program, 2011-2015

\begin{tabular}{|c|c|c|c|c|c|c|c|}
\hline \multirow[b]{2}{*}{ Variable } & \multirow[b]{2}{*}{ 30-day mortality (\%) } & \multicolumn{2}{|c|}{ Risk group only } & \multicolumn{2}{|c|}{$\begin{array}{l}\text { Adjusted for day of AKI } \\
\text { diagnosis }\end{array}$} & \multicolumn{2}{|c|}{$\begin{array}{l}\text { Adjusted for day of AKI diagnosis and } \\
\text { procedure category } \dagger\end{array}$} \\
\hline & & HR & $95 \% \mathrm{CI}$ & $\mathrm{HR}$ & $95 \% \mathrm{CI}$ & HR & $95 \% \mathrm{CI}$ \\
\hline Group A & 18 & 1.00 & & 1.00 & & 1.00 & \\
\hline Group B & 31 & $1.79 *$ & (1.52 to 2.05$)$ & $1.73 *$ & (1.47 to 1.99$)$ & $1.81 *$ & (1.53 to 2.06$)$ \\
\hline Group C & 53 & $3.55^{*}$ & (2.87 to 3.88$)$ & $3.22 *$ & (2.61 to 3.53$)$ & $3.39 *$ & (2.69 to 3.74$)$ \\
\hline Day of AKI diagnosis & & & & $0.97 *$ & (0.96 to 0.98$)$ & $0.97 *$ & (0.96 to 0.98$)$ \\
\hline
\end{tabular}

$\mathrm{AKI}=$ acute kidney injury; $\mathrm{CI}=$ confidence interval; $\mathrm{HR}=$ hazard ratio

Confidence intervals determined by bootstrapping

Adjustment for procedure category based on the Clinical Classifications Software of the Agency for Healthcare Research and Quality

$* P<0.0001$

$\dagger$ Hazard ratios for procedure categories not displayed

and 2); thus, preoperative renal function, though not directly related to mortality, nevertheless influenced the patient's comorbid state.

The separation of patients into latent risk classes also allowed for the identification of different patterns in the timing of postoperative AKI: an "early" diagnosis group and a "late" diagnosis group. The early group (classes 5-7) comprised $31 \%$ of sample, with $29 \%$ developing AKI by POD 1 and $53 \%$ by POD 3 . In contrast, the late diagnosis group (classes 1-4) had only $10 \%$ of AKI diagnosed by POD 1 and the median day of AKI diagnosis was POD 9. Interestingly, class 5 patients, though they developed early AKI, did not have the same severe mortality as the other patients with early AKI, indicating that their lower comorbidity burden had a mitigating effect on subsequent mortality. Regardless of the patient's risk class, there was a clear and consistent effect of the actual timing of postoperative AKI, with each additional POD without AKI decreasing the hazard for mortality by $\sim 3 \%$.

In a subset of patients for whom preoperative risk stratification information was available, we found that the risk of post-AKI mortality was not simply a reflection of their preoperative mortality risk. In fact, the correlation between preoperative risk class and post-AKI risk class was negative, suggesting that patients thought to have low mortality risk prior to surgery had more dramatic increases in mortality risk if AKI developed, compared with those in the highest preoperative risk strata. Thus, a thorough reevaluation of a patient's risk profile in the setting of a major postoperative complication is necessary and preoperative perceptions may not still be valid. As this was a post hoc analysis, future studies comparing preoperative and post-complication risk stratification will help clarify how events in the postoperative course modify a patient's subsequent mortality risk.

The use of LCA represents a unique framework for evaluating the effects of risk factors on mortality by positing the existence of a latent variable, the comorbid state, that is associated with mortality rather than individual variables, ${ }^{10,11}$ and allows for a more nuanced understanding of the relationships between individual variables and their effects on mortality. LCA is widely used in social science research but has been applied to clinical datasets to identify subphenotypes of acute respiratory distress syndrome patients, ${ }^{25}$ asthma patients, ${ }^{26}$ and most recently to establish comorbidity profiles in patients undergoing surgery for colorectal cancer. $^{27}$ Only variables known preoperatively were incorporated in the LCA model as the preoperative comorbid state was the focus of the analysis, but other intraoperative and postoperative factors, such as individualized intraoperative blood pressure management, ${ }^{28,29}$ intraoperative oliguria, ${ }^{30}$ and other postoperative complications ${ }^{8}$ are clearly associated with postoperative AKI and mortality. Future studies will identify the relationships that the preoperative comorbid state and these other factors have to influence postoperative mortality.

The assignment of the latent classes was determined from a probabilistic model so there was the possibility that an individual was assigned to the wrong class. Nevertheless, the bootstrapped samples accounted for this uncertainty regarding class assignment and so the CIs should have given an adequate sense of how precise the hazard ratio estimates were in the regression models. Most latent classes had survival curves and 30-day mortality estimates that were not statistically significantly different between the derivation and validation cohorts, but only class 3 had significantly different survival and mortality (Supplemental Fig. 3C; Supplemental Table 4, available as ESM). Class 3 was the smallest class in both the derivation $(n=431,10.9 \%)$ and validation $(n=96,5.9 \%)$ cohorts, and it is likely that this small size contributed to these differences. In addition, a bootstrapped analysis of the 
Table 3 Cox models for mortality after acute kidney injury diagnosis in high-risk intraabdominal general surgery patients, American College of Surgeons National Surgical Quality Improvement Program, 2011-2015

\begin{tabular}{|c|c|c|c|c|c|c|c|c|}
\hline \multirow[b]{4}{*}{ Variable } & & & \multicolumn{6}{|c|}{ Stratified by latent risk group } \\
\hline & \multirow{2}{*}{\multicolumn{2}{|c|}{$\begin{array}{l}\text { Entire cohort } \\
n=3,939\end{array}$}} & \multirow{2}{*}{\multicolumn{2}{|c|}{$\frac{\text { Group A }}{n=1,620}$}} & \multirow{2}{*}{\multicolumn{2}{|c|}{$\frac{\text { Group B }}{n=1,536}$}} & \multirow{2}{*}{\multicolumn{2}{|c|}{$\frac{\text { Group C }}{n=783}$}} \\
\hline & & & & & & & & \\
\hline & HR & $95 \% \mathrm{CI}$ & HR & $95 \% \mathrm{CI}$ & HR & $95 \% \mathrm{CI}$ & HR & $95 \% \mathrm{CI}$ \\
\hline Day of AKI diagnosis & $0.97 *$ & (0.96 to 0.98$)$ & $0.97 *$ & (0.95 to 0.99$)$ & $0.97 *$ & $(0.96$ to 0.99$)$ & $0.96^{*}$ & (0.94 to 0.98$)$ \\
\hline Female & $0.86^{*}$ & $(0.75$ to 0.97$)$ & 0.77 & $(0.58$ to 1.01$)$ & $0.75 *$ & $(0.61$ to 0.92$)$ & 0.89 & $(0.72$ to 1.11$)$ \\
\hline Age (yr) & $*$ & & & & $*$ & & $*$ & \\
\hline \multicolumn{9}{|l|}{$(\operatorname{Ref}=$ Age $>50$ to $\leq 60)$} \\
\hline$\leq 40$ & 0.54 & $(0.36$ to 0.83$)$ & 0.54 & $(0.28$ to 1.03$)$ & 0.58 & $(0.29$ to 1.15$)$ & 0.38 & $(0.13$ to 1.10$)$ \\
\hline$>40$ to $\leq 50$ & 0.89 & (0.67 to 1.18$)$ & 0.70 & $(0.45$ to 1.11$)$ & 1.11 & (0.68 to 1.80$)$ & 1.02 & (0.55 to 1.88$)$ \\
\hline$>50$ to $\leq 60$ & 1.00 & & 1.00 & & 1.00 & & 1.00 & \\
\hline$>60$ to $\leq 70$ & 1.21 & (1.00 to 1.47$)$ & 1.17 & (0.86 to 1.58$)$ & 1.01 & (0.71 to 1.44$)$ & 1.51 & (1.00 to 2.27$)$ \\
\hline$>70$ to $\leq 80$ & 1.57 & (1.28 to 1.91$)$ & 1.13 & (0.76 to 1.68$)$ & 1.59 & (1.12 to 2.26$)$ & 1.97 & (1.30 to 2.98$)$ \\
\hline$>80$ & 1.91 & (1.52 to 2.40$)$ & & & 1.89 & (1.30 to 2.77$)$ & 2.15 & (1.39 to 3.33$)$ \\
\hline Body mass index $\left(\mathrm{kg} \cdot \mathrm{m}^{-2}\right)$ & $*$ & & $*$ & & & & & \\
\hline \multicolumn{9}{|l|}{$(\operatorname{Ref}=>18.5$ to $\leq 25)$} \\
\hline$\leq 18.5$ & 1.22 & (0.89 to 1.67$)$ & 1.66 & $(0.77$ to 3.58$)$ & 1.90 & (1.16 to 3.13$)$ & 0.90 & (0.55 to 1.47$)$ \\
\hline$>18.5$ to $\leq 25$ & 1.00 & & 1.00 & & 1.00 & & 1.00 & \\
\hline$>25$ to $\leq 30$ & 0.84 & $(0.71$ to 0.98$)$ & 0.66 & $(0.47$ to 0.93$)$ & 0.94 & $(0.73$ to 1.21$)$ & 0.86 & (0.65 to 1.15$)$ \\
\hline$>30$ to $\leq 35$ & 0.73 & $(0.60$ to 0.87$)$ & 0.51 & $(0.35$ to 0.74$)$ & 0.92 & (0.69 to 1.23$)$ & 0.71 & (0.51 to 0.97$)$ \\
\hline$>35$ & 0.81 & $(0.68$ to 0.97$)$ & 0.75 & $(0.52$ to 1.07$)$ & 0.92 & $(0.68$ to 1.25$)$ & 0.74 & (0.54 to 1.02$)$ \\
\hline Emergency & 1.36 & (1.16 to 1.60$)$ & 1.26 & $(0.68$ to 2.33$)$ & $1.40 *$ & (1.08 to 1.81$)$ & 1.05 & $(0.73$ to 1.50$)$ \\
\hline Functionally dependent & 1.13 & (0.94 to1.24) & 1.23 & $(0.29$ to 5.29$)$ & $1.35^{*}$ & (1.02 to 1.78$)$ & 0.94 & (0.73 to 1.22$)$ \\
\hline Current smoker & 1.06 & (0.91 to 1.24$)$ & 1.08 & (0.81 to 1.44$)$ & 0.82 & (0.63 to 1.08$)$ & $1.34^{*}$ & (1.02 to 1.75$)$ \\
\hline Hypertension & 0.97 & $(0.84$ to 1.12$)$ & 0.84 & (0.64 to 1.10$)$ & 1.14 & (0.89 to 1.46$)$ & 0.84 & (0.64 to 1.09$)$ \\
\hline Congestive heart failure & 1.16 & (0.92 to 1.47$)$ & & & 1.24 & (0.89 to 1.74$)$ & 1.06 & (0.75 to 1.49$)$ \\
\hline Diabetes & 0.97 & (0.85 to 1.12$)$ & 0.97 & (0.73 to 1.30$)$ & 0.95 & $(0.76$ to 1.20$)$ & 0.95 & (0.74 to 1.21$)$ \\
\hline Dyspnea & $1.20 *$ & (1.03 to 1.41$)$ & 1.30 & (0.88 to 1.92$)$ & $1.42 *$ & (1.11 to 1.82$)$ & 0.96 & (0.74 to 1.24$)$ \\
\hline Ventilator dependent & $1.28 *$ & (1.05 to 1.55$)$ & & & $2.24 *$ & (1.53 to 3.30$)$ & 1.16 & (0.91 to 1.47$)$ \\
\hline Chronic obstructive pulmonary disease & 1.17 & (0.98 to 1.39$)$ & 1.33 & $(0.84$ to 2.11$)$ & 1.18 & $(0.89$ to 1.56$)$ & 1.07 & (0.81 to 1.42$)$ \\
\hline Ascites & $1.57 *$ & (1.27 to 1.94$)$ & 1.54 & $(0.78$ to 3.04$)$ & $1.71 *$ & $(1.20$ to 2.45$)$ & $1.57 *$ & (1.16 to 2.14$)$ \\
\hline Wound infection & 0.90 & (0.70 to 1.15$)$ & 0.52 & $(0.13$ to 2.14$)$ & 0.98 & $(0.67$ to 1.44$)$ & 0.79 & $(0.56$ to 1.12$)$ \\
\hline Steroid use & 1.20 & (1.00 to 1.45$)$ & 1.04 & $(0.63$ to 1.73$)$ & 1.28 & (0.93 to 1.78$)$ & 1.17 & (0.89 to 1.55$)$ \\
\hline Bleeding disorders & $1.26^{*}$ & (1.07 to 1.47$)$ & 1.29 & (0.79 to 2.08$)$ & 1.20 & (0.93 to 1.56$)$ & 1.17 & (0.94 to 1.47$)$ \\
\hline Preoperative transfusion & 1.11 & $(0.92$ to 1.35$)$ & 0.74 & $(0.23$ to 2.38$)$ & $1.41 *$ & (1.01 to 1.98$)$ & 1.07 & (0.81 to 1.40$)$ \\
\hline Sepsis/septic shock & $1.50 *$ & (1.28 to 1.76$)$ & 0.95 & (0.52 to 1.74$)$ & $1.39 *$ & (1.08 to 1.78$)$ & $1.98^{*}$ & (1.29 to 3.04$)$ \\
\hline Disseminated cancer & $1.38 *$ & (1.16 to 1.65 ) & 1.27 & (0.94 to 1.72$)$ & $1.38 *$ & (1.03 to 1.84 ) & 1.28 & (0.89 to 1.85$)$ \\
\hline \multirow{2}{*}{\multicolumn{9}{|c|}{$\begin{array}{l}\text { Estimated glomerular filtration rate } \\
\quad\left(\mathrm{mL} \cdot \min ^{-1} 1.73 \mathrm{~m}^{-2}\right) \\
(\operatorname{Ref}=>90)\end{array}$}} \\
\hline & & & & & & & & \\
\hline Missing & 0.70 & (0.34 to 1.43$)$ & 0.79 & (0.33 to 1.90$)$ & 0.19 & (0.02 to 1.86$)$ & 2.60 & (0.32 to 21.0$)$ \\
\hline$\leq 15$ & 0.81 & (0.56 to 1.18$)$ & & & 0.60 & (0.31 to 1.13$)$ & 0.87 & (0.44 to 1.73$)$ \\
\hline$>15$ to $\leq 30$ & 1.11 & (0.88 to 1.40$)$ & & & 1.13 & (0.76 to 1.68$)$ & 1.21 & (0.69 to 2.13 ) \\
\hline$>30$ to $\leq 60$ & 1.09 & (0.89 to 1.33$)$ & 1.06 & (0.73 to 1.56$)$ & 1.00 & (0.70 to 1.44$)$ & 1.22 & (0.70 to 2.13$)$ \\
\hline$>60$ to $\leq 90$ & 1.11 & (0.91 to 1.34$)$ & 1.10 & (0.83 to 1.46$)$ & 1.16 & (0.81 to 1.66$)$ & 1.34 & (0.73 to 2.47$)$ \\
\hline$>90$ & 1.00 & & 1.00 & & 1.00 & & 1.00 & \\
\hline Hematocrit (\%) & $*$ & & $*$ & & & & $*$ & \\
\hline$(\operatorname{Ref}=>38)$ & & & & & & & & \\
\hline
\end{tabular}


Table 3 continued

\begin{tabular}{|c|c|c|c|c|c|c|c|c|}
\hline \multirow[b]{4}{*}{ Variable } & & & \multicolumn{6}{|c|}{ Stratified by latent risk group } \\
\hline & \multirow{2}{*}{\multicolumn{2}{|c|}{$\begin{array}{l}\text { Entire cohort } \\
n=3,939\end{array}$}} & \multirow{2}{*}{\multicolumn{2}{|c|}{$\frac{\text { Group A }}{n=1,620}$}} & \multirow{2}{*}{\multicolumn{2}{|c|}{$\frac{\text { Group B }}{n=1,536}$}} & \multirow{2}{*}{\multicolumn{2}{|c|}{$\frac{\text { Group C }}{n=783}$}} \\
\hline & & & & & & & & \\
\hline & $\mathrm{HR}$ & $95 \% \mathrm{CI}$ & HR & $95 \% \mathrm{CI}$ & HR & $95 \% \mathrm{CI}$ & HR & $95 \% \mathrm{CI}$ \\
\hline Missing & 2.64 & (1.37 to 5.09$)$ & 4.09 & (1.71 to 9.78$)$ & 2.60 & (0.69 to 9.84$)$ & 27.5 & (3.43 to 220$)$ \\
\hline$\leq 34$ & 1.13 & $(0.98$ to 1.31$)$ & 1.23 & (0.90 to 1.69$)$ & 1.02 & $(0.80$ to 1.30$)$ & 1.10 & (0.83 to 1.45$)$ \\
\hline$>34$ to $\leq 38$ & 1.11 & (0.94 to 1.32$)$ & 1.39 & (1.03 to 1.86$)$ & 1.13 & (0.85 to 1.49$)$ & 0.80 & (0.56 to 1.14$)$ \\
\hline$>38$ & 1.00 & & 1.00 & & 1.00 & & 1.00 & \\
\hline
\end{tabular}

$\mathrm{AKI}=$ acute kidney injury; $\mathrm{CI}=$ confidence interval; $\mathrm{HR}=$ hazard ratio

All models also adjusted for procedure based on the Clinical Classifications Software of the Agency for Healthcare Research and Quality

$* P<0.05$; for multi-level categorical variables. $P$-value for the Type 3 Wald test for overall effect of the variable is indicated

validation cohort did not support a true difference in survival between the derivation and validation cohorts for patients in class 3 (data not shown). Nonetheless, when combined with classes 4 and 5, there were no survival differences between the derivation and validation cohorts in the combined group B (Supplemental Fig. 3H, available as ESM). Future studies will be necessary to confirm the validity of our model.

The ACS-NSQIP definition of AKI required an increase in creatinine levels of at least $2 \mathrm{mg} \cdot \mathrm{dl}^{-1}$, which was significantly higher than the most recent consensus KDIGO criteria requiring an increase of at least $27 \mu \mathrm{mol} \cdot \mathrm{L}^{-1}$ $\left(0.3 \mathrm{mg} \cdot \mathrm{dl}^{-1}\right){ }^{31}$ As such, the current analyses only accounted for patients who developed severe AKI and it is unknown whether the preoperative comorbid state would have the same associations with mortality in patients with milder forms of AKI. Other limitations of the study included the inherent limitations of observational studies, ${ }^{32}$ such as residual confounding because of variables not captured in the dataset that might be important in determining the comorbid state and the lack of generalizability because the ACS-NSQIP is overrepresented by larger, academic centres. ${ }^{33}$

In conclusion, in a cohort of patients developing severe AKI after high-risk intraabdominal general surgery, we used LCA to identify distinct classes of patients based on their preoperative comorbidities and risk factors. The identified comorbid states were significantly associated with survival after AKI diagnosis. While other factors clearly affect mortality after AKI, the preoperative comorbid state can be used to establish a baseline risk of mortality in patients with AKI, but the modifying effects of other factors need to be established in future studies.

Acknowledgements This publication was supported by the National Centre for Advancing Translational Sciences, National Institutes of Health through Grant Number KL2TR001874 (MK). The content is solely the responsibility of the authors and does not necessarily represent the official views of the NIH.
Conflicts of interest None declared.

Editorial responsibility This submission was handled by Dr. Hilary P. Grocott, Editor-in-Chief, Canadian Journal of Anesthesia.

Author contributions Minjae Kim contributed substantially to all aspects of this manuscript, including conception and design, acquisition, analysis, and interpretation of data and drafting the article. Melanie M. Wall, Ravi P. Kiran, and Guohua Li contributed substantially to the analysis and interpretation of data, and drafting the article.

\section{References}

1. Hobson C, Ozrazgat-Baslanti T, Kuxhausen A, et al. Cost and mortality associated with postoperative acute kidney injury. Ann Surg 2015; 261: 1207-14.

2. Bihorac A, Yavas $S$, Subbiah S, et al. Long-term risk of mortality and acute kidney injury during hospitalization after major surgery. Ann Surg 2009; 249: 851-8.

3. Collister D, Рannu N, Ye F, et al. Health care costs associated with AKI. Clin J Am Soc Nephrol 2017; 12: 1733-43.

4. Kim M, Brady JE, Li G. Variations in the risk of acute kidney injury across intraabdominal surgery procedures. Anesth Analg 2014; 119: 1121-32.

5. Meersch M, Schmidt C, Zarbock A. Perioperative acute kidney injury: an under-recognized problem. Anesth Analg 2017; 125 : 1223-32.

6. Kheterpal S, Tremper KK, Heung M, et al. Development and validation of an acute kidney injury risk index for patients undergoing general surgery: results from a national data set. Anesthesiology 2009; 110: 505-15.

7. Kheterpal S, Tremper KK, Englesbe MJ, et al. Predictors of postoperative acute renal failure after noncardiac surgery in patients with previously normal renal function. Anesthesiology 2007; 107: 892-902.

8. Kim $M, L i$ G. Two-way interaction effects of perioperative complications on 30-day mortality in general surgery. World $\mathbf{J}$ Surg 2018; 42: 2-11.

9. Uebersax JS. LCA Frequently Asked Questions (FAQ). Last updated July 2009. Available from URL: http://www.johnuebersax.com/stat/faq.htm (accessed July 2018). 
10. Kim M, Wall MM, Li G. Applying latent class analysis to risk stratification for perioperative mortality in patients undergoing intraabdominal general surgery. Anesth Analg 2016; 123: 193205.

11. Kim M, Wall MM, Li G. Risk stratification for major postoperative complications in patients undergoing intraabdominal general surgery using latent class analysis. Anesth Analg 2018; 126: 848-57.

12. Fink AS, DA Campbell J, Mentzer RM Jr, et al. The National Surgical Quality Improvement Program in non-veterans administration hospitals: initial demonstration of feasibility. Ann Surg 2002; 236: 344-53.

13. World Health Organization. Obesity : preventing and managing the global epidemic : report of a WHO consultation. Geneva: World Health Organization; 2000. Available from URL: http:// www.who.int/nutrition/publications/obesity/WHO_TRS_894/en/ (accessed July 2018).

14. Levey AS, Stevens LA, Schmid CH, et al. A new equation to estimate glomerular filtration rate. Ann Intern Med 2009; 150: 604-12.

15. National Kidney Foundation. K/DOQI clinical practice guidelines for chronic kidney disease: evaluation, classification, and stratification. Am J Kidney Dis 2002; 39(2 Suppl 1): S1-266.

16. Rabe-Hesketh $S$, Skrondal A. Classical latent variable models for medical research. Stat Methods Med Res 2008; 17: 5-32.

17. Bartholomew D, Knott M, Moustaki I. Latent Variable Models and Factor Analysis : a Unified Approach - Third Edition. Chichester, West Sussex: Wiley; 2011.

18. Schwarz G. Estimating the dimension of a model. Ann Statist 1978; 6: 461-4.

19. Nylund KL, Asparouhov T, Muthén BO. Deciding on the number of classes in latent class analysis and growth mixture modeling: a Monte Carlo simulation study. Structural Equation Modeling 2007; 14: 535-69.

20. Enders $C K$, Bandalos $D L$. The relative performance of full information maximum likelihood estimation for missing data in structural equation models. Structural Equation Modeling 2001; 8: 430-57.

21. Kaplan EL, Meier P. Nonparametric estimation from incomplete observations. J Am Stat Assoc 1958; 53: 457-81.
22. Peto R, Peto J. Asymptotically efficient rank invariant test procedures. J R Stat Soc A 1972; 135: 185-207.

23. Armstrong $R A$. When to use the Bonferroni correction. Ophthalmic Physiol Opt 2014; 34: 502-8.

24. Kim $M, L i G$. Postoperative complications affecting survival after cardiac arrest in general surgery patients. Anesth Analg 2018; 126: 858-64.

25. Calfee CS, Delucchi K, Parsons PE, et al. Subphenotypes in acute respiratory distress syndrome: latent class analysis of data from two randomised controlled trials. Lancet Respir Med 2014; 2: 611-20.

26. Howard $R$, Rattray $M$, Prosperi M, Custovic A. Distinguishing asthma phenotypes using machine learning approaches. Curr Allergy Asthma Rep 2015; 15: 38.

27. Hahn EE, Gould MK, Munoz-Plaza CE, Lee JS, Parry C, Shen E. Understanding comorbidity profiles and their effect on treatment and survival in patients with colorectal cancer. J Natl Compr Canc Netw 2018; 16: 23-34.

28. Futier E, Lefrant JY, Guinot PG, et al. Effect of individualized vs standard blood pressure management strategies on postoperative organ dysfunction among high-risk patients undergoing major surgery: a randomized clinical trial. JAMA 2017; 318: 1346-57.

29. Wu X, Jiang Z, Ying J, Han Y, Chen Z. Optimal blood pressure decreases acute kidney injury after gastrointestinal surgery in elderly hypertensive patients: a randomized study: optimal blood pressure reduces acute kidney injury. J Clin Anesth 2017; 43: 7783.

30. Mizota T, Yamamoto Y, Hamada M, Matsukawa S, Shimizu S, Kai $S$. Intraoperative oliguria predicts acute kidney injury after major abdominal surgery. Br J Anaesth 2017; 119: 1127-34.

31. National Kidney Foundation. Kidney Disease: Improving Global Outcomes (KDIGO) Acute Kidney Injury Work Group. KDIGO clinical practice guideline for acute kidney injury. Kidney Int Suppl 2012; 2: 19-36.

32. Hill HA, Kleinbaum DG. Bias in observational studies. Encyclopedia of Biostatistics 2005; 1.

33. Dimick JB, Osborne NH, Hall BL, Ko CY, Birkmeyer JD. Risk adjustment for comparing hospital quality with surgery: how many variables are needed? J Am Coll Surg 2010; 210: 503-8. 